\begin{tabular}{|c|c|}
\hline 95 & Malaysian Journal of Social Sciences and Humanities (MJSSH) \\
\hline Malaysian Journal of & Volume 5, Issue 1, January 2020 \\
\hline $\begin{array}{l}\text { Humantitis } \\
\text { (MJ - sSH) }\end{array}$ & e-ISSN : 2504-8562 \\
\hline & $\begin{array}{l}\text { Journal home page: } \\
\text { www.msocialsciences.com }\end{array}$ \\
\hline
\end{tabular}

\title{
Amalan Inovasi Pembungkusan Produk Usahawan Mikro di Selangor
}

\author{
Mahani Amat' ${ }^{1}$, Suraiya Ishak ${ }^{1}$ \\ 1Pusat Pembangunan, Sosial dan Persekitaran, Fakulti Sains Sosial dan Kemanusiaan, Universiti Kebangsaan Malaysia \\ (UKM) \\ Correspondence: Mahani Amat (mahanihalimi@gmail.com)
}

\begin{abstract}
Abstrak
Artikel ini bertujuan untuk mendeskripsi amalan inovasi pembungkusan produk dalam kalangan usahawan mikro di bawah bimbingan agensi di negeri Selangor. Seramai 40 orang usahawan mikro makanan di negeri Selangor telah diambil sebagai sampel kajian melalui teknik pensampelan rawak sistematik. Instrumen kajian ini merupakan soal selidik dengan enam skala Likert yang mengandungi lapan item yang telah disahkan oleh pakar-pakar penilai dan mempunyai nilai kebolehpercayaan yang baik. Data kajian ini dianalisis secara statistik deskriptif iaitu berasaskan nilai min dan peratusan. Dapatan kajian menunjukkan purata peratusan dan nilai min keseluruhan bagi amalan inovasi pembungkusan adalah berada pada tahap yang tinggi. Oleh itu, dapatan kajian ini menunjukkan bahawa usahawan mikro di bawah bimbingan agensi di negeri Selangor ada melakukan inovasi terhadap pembungkusan produk sejurus mendapat bimbingan daripada agensi terutamanya dalam penambahbaikan informasi maklumat, rupa bentuk, warna dan reka grafik.
\end{abstract}

Kata kunci: amalan, inovasi pembungkusan, usahawan mikro

\section{Packaging Innovation Practices Among Micro Entrepreneurs in Selangor}

\begin{abstract}
This article aims to describe the innovation practices of product packaging among micro entrepreneurs under the guidance of agencies in the state of Selangor. About 40 micro entrepreneurs in the food industry in Selangor were taken as a sample of this study using sistematic random sampling techniques. This research instrument was a questionnaire with six Likert scale consisting of eight items which has been verified by expert subject matters and have a good realibility. The data were analyzed using descriptive statistics which is based on mean value and percentage. The findings of thus study showed that the average of percentages and overall value of mean for packaging innovation practice are at a high level. Therefore, the findings of this study show that micro entrepreneurs under the guidance of agencies in the state of Selangor are innovating on product packaging after receiving guidance from the agency especially in the improvement of information, shape, color and graphic design.
\end{abstract}

Keywords: practices, packaging innovation, micro enterpreneurs 


\section{Pengenalan}

Perusahaan kecil dan sederhana (PKS) di Malaysia merupakan tunjang utama kepada keluaran dalam negara kasar (KDNK) dan ekonomi negara apabila 98.5\% pertubuhan perniagaan yang berdaftar adalah PKS yang meliputi keseluruhan saiz dan sektor perniagaan (SME Corporation 2018). Manakala, penyumbang utama dalam PKS iaitu $76.5 \%$ adalah terdiri daripada perusahaan mikro (SME Corporation 2018). Justeru, sedar akan sumbangan usahawan mikro dalam ekonomi Negara dan pentingnya inovasi pembungkusan, maka, pelbagai program pembangunan pembungkusan dan perkhidmatan berkaitan pembungkusan telah disediakan oleh pelbagai agensi pembangunan usahawan untuk dimanfaatkan. Sejumlah RM300 juta telah diperuntukkan untuk melaksanakan program pembangunan modal insan oleh agensi pembangunan usahawan yang bertujuan untuk meningkatkan pengetahuan usahawan (SME Corporation 2018). Malah, usahawan mikro terpilih turut mendapat bimbingan intensif daripada agensi pembimbing seperti peralatan pembungkusan, geran, khidmat nasihat dan teknologi pembungkusan dengan harapan mereka dapat melakukan inovasi pembungkusan selepas mendapat bimbingan agensi.

Lazimnya, perusahaan mikro bersifat kecil, penggunaan teknologi yang rendah, kurang berdaya saing dan pasaran produk adalah setempat. Kesukaran yang digambarkan ini juga disebabkan kekangan modal dan kurangnya pengetahuan yang memberikan kesan pada penampilan pembungkusan. Majoriti usahawan mikro gagal meningkatkan penampilan imej pembungkusan yang menarik (Wang \& Shapira 2012;Kiumarsi, Jayaraman, Salmi, \& Varastegani 2014), pembungkusan yang kurang informasi dan penggunaan bahan pembungkusan yang kurang berkualiti (Ahmad Zaki 2011; Ampuero \& Vila 2006). Kajian lepas membuktikan pengguna memberikan reaksi positif dalam membeli sesuatu produk disebabkan oleh pembungkusan yang menarik (Magnier, Schoormans, \& Mugge 2016) dan berinformasi (Luminer, Lakewood \& N.J., 2017), memberikan keselesaan penggunaan dan ketahanan (Wyrwa \& Barska 2017) berbanding apabila ia dibungkus dalam pembungkusan konvensional. Hal ini menggambarkan penambahbaikan yang dibuat pada pek pembungkusan dapat menarik perhatian pengguna untuk membeli dan seterusnya kekal relevan dalam pasaran yang sangat kompetitif pada hari ini (Kotler \& Armstrong 2012). Malah, lebih daripada 80\% usahawan di Amerika Syarikat menyatakan pembungkusan adalah 'jurujual' dalam pemasaran (Anon. 2018a).

Kajian lepas berkaitan pembungkusan produk makanan banyak memfokuskan kajian terhadap pengguna dalam membuat keputusan untuk membeli (Azad \& Masoumi 2012; Beneke, Mathews, Munthree, \& Pillay 2015; Kurtkoti 2016; Siti Hasnah, Wai Leng, \& Wong Wai 2012; Tinne 2016; Zekiri \& Hasani 2015) dan kajian berkaitan faktor-faktor kejayaan atau kegagalan sesebuah perniagaan (Alfoqahaa 2018; Atiqah, Binti, Nazri, \& Azmi 2016; Islam \& Muktadir-Al-Mukit 2016; Jernström, Karvonen, Kässi, Kraslawski, \& Hallikas 2017; Sayal \& Banerjee 2017; Suhaila, Suhaily, \& Muhammad Firdaus 2014). Manakala, kajian berkaitan inovasi pula lebih memfokuskan kepada inovasi produk, inovasi proses, inovasi peralatan dan inovasi pemasaran berbanding inovasi pembungkusan (Suraiya, Abd Hair, Mohd Yusof, Ahmad Raflis, Sarmila, Suhana, Zaimah, \& Azima 2015; Zaim Shah \& Hartini 2016). Malah, kajian yang dijalankan juga tidak banyak membincangkan tahap amalan inovasi pembungkusan di kalangan usahawan mikro. Kajian Esa, Ab.Hadi dan Mohd Yunos (2002) pula mendapati amalan peniaga kecil terhadap etika perniagaan adalah sederhana. Dapatan tersebut secara tidak langsung menunjukkan bahawa tingkah laku manusia adalah bersifat terancang. Lantaran itu, terdapat jurang kajian yang perlu dikaji mengenai amalan inovasi pembungkusan produk makanan usahawan mikro di bawah bimbingan agensi.

\section{Pernyataan Masalah}

Kerajaan menyasarkan lebih banyak produk usahawan dapat dipasarkan di pasaraya (Anon. 2018b) dan menjelang tahun 2020 kerajaan menyasarkan $50 \%$ usahawan mikro berjaya migrasi ke status PKS (Anon. 2018c). Pada masa ini, hanya 1,169 produk PKS atau $20 \%$ sahaja yang berjaya menembusi pasaraya (Anon. 2018b). Kelemahan yang paling ketara adalah disebabkan kualiti pembungkusan yang tidak mencapai tahap piawaian yang ditetapkan seperti penggunaan bahan pembungkus yang tidak berkualiti, informasi yang tidak lengkap, reka bentuk dan reka grafik yang tidak menarik, dan kaedah 
pembungkusan yang kurang sesuai (Ahmad Zaki 2011; Anon. 2014, 2018d). Masalah ini cuba diatasi oleh agensi pembimbing dengan menyediakan pelbagai bentuk bantuan dan perkhidmatan pembungkusan seperti latihan, geran, peralatan, khidmat nasihat dan pembangunan reka bentuk pembungkusan. Bantuan yang diberikan diharapkan dapat membantu usahawan menghasilkan produk dengan penampilan pembungkusan yang lebih menarik. Hal ini bagi memastikan usahawan IKS di Malaysia mampu memasarkan produk yang berkualiti dan mampu bersaing dengan pesaing hingga ke pasaran global.

Persoalannya, sejauhmanakah usahawan mikro yang di bawah program bimbingan agensi tertentu di Selangor telah mempraktikkan inovasi pembungkusan produk mereka? Oleh itu, objektif kertas kerja ini adalah untuk mendeskripsi amalan inovasi pembungkusan produk dalam kalangan usahawan mikro di bawah bimbingan agensi di negeri Selangor. Kajian ini penting untuk dilaksanakan sebab penambahbaikan amalan dalam inovasi pembungkusan produk akan membantu meningkatkan pemasaran produk seperti yang dicadangkan oleh Kalsonm dan Ab. Rahim, (2015) untuk melakukan kajian lanjutan bagi menganalisis tingkah laku usahawan bagi melihat amalan pemasaran dalam mencapai tahap prestasi yang lebih tinggi. Usahawan mikro perlu membuat penambahbaikan terhadap pembungkusan seperti imej produk, penggunaan warna dan informasi pada pembungkusan, penggunaan bahan pembungkus yang berkualiti dan sesuai bagi meningkatkan pasaran dan reputasi penampilan pembungkusan. Oleh itu, tahap amalan usahawan dalam menghasilkan inovasi pembungkusan dilihat dan dikaji.

\section{Kaedah Kajian}

Reka bentuk kajian ini merupakan jenis kuantitatif secara tinjauan yang menggunakan borang soal selidik. Satu set soal selidik digunakan untuk tujuan pengumpulan data. Kajian ini telah dijalankan di negeri Selangor dan populasi kajian adalah 54 orang usahawan mikro makanan yang telah mendapat bimbingan pembungkusan daripada agensi seperti Jabatan Pertanian, MARDI, FAMA dan UPEN Selangor. Jumlah sampel kajian yang diperolehi dalam kajian ini adalah 40 sampel dan bilangan sampel yang diperlukan mencukupi berdasarkan jadual pengiraan saiz sampel kajian yang dikemukakan oleh perisian Raosoft (Raosoft 2004).

Kaedah pensampelan menggunakan teknik pensampelan rawak sistematik. Instrumen kajian ini terdiri daripada soal selidik yang diubahsuai berdasarkan kajian-kajian lepas selaras dengan objektif kajian. Instrumen ini terdiri daripada 8 item yang telah disahkan oleh 4 orang pakar penilai dalam bidang keusahawanan dan perniagaan, teknologi pembungkusan makanan, dan pembangunan sumber manusia dan penilaian latihan, 2 orang pegawai agensi di agensi pembimbing dan 2 orang usahawan dalam bidang perusahaan makanan. Nilai kebolehpercayaan cronbach's alpha iaitu 0.983. Menurut Hair, Money, Page dan Samouel (2007) nilai cronbach's alpha yang melebihi 0.7 dikategorikan sebagai item yang mempunyai kebolehpercayaan yang baik.

Data kajian diperoleh melalui edaran borang soal selidik kepada usahawan secara pertemuan bersemuka, melalui pos dan pengisian secara maya menggunakan google dokumen. Bagi meningkatkan maklum balas, usahawan dihubungi dan diberikan peringatan mesra berulang kali serta diberikan e-book berkaitan pemasaran kepada usahawan yang telah memberikan maklum balas.

Dalam kajian ini, analisis deskriptif digunakan bagi menjawab objektif kajian. Tahap amalan inovasi pembungkusan yang dikaji adalah menggunakan peratusan, frekuensi dan min seterusnya analisis tahap interpretasi diambil kira daripada nilai enam mata iaitu nilai tertinggi 6.00 di bahagikan kepada tiga tahap, iaitu rendah $(\min =0.00-2.49)$, sederhana $(\min =2.50-4.49)$ dan tinggi $(\min =4.50-6.00)$. Jadual 1 menunjukkan interpretasi min yang digunakan dalam dapatan kajian.

Jadual 1: Interpretasi min

\begin{tabular}{cc}
\hline Julat Min & Interpretasi \\
\hline $0.00-2.49$ & Rendah \\
$2.50-4.49$ & Sederhana \\
\hline
\end{tabular}


DOI: https://doi.org/10.47405/mjssh.v5i1.347

$\frac{\text { Tinggi }}{4.50-6.00}$

\section{Dapatan Kajian dan Perbincangan}

Jadual 2 menunjukkan analisis tahap amalan bagi setiap item amalan inovasi pembungkusan usahawan di bawah bimbingan agensi. Hasil dapatan kajian menunjukkan kesemua lapan item tersebut mempunyai skor min yang tinggi. Item yang mempunyai skor yang tertinggi adalah saya memperbaiki informasi maklumat pada pembungkusan $(\mathrm{min}=5.45)$ dengan jumlah peratus responden yang sangat setuju adalah sebanyak $47.5 \%$, setuju adalah sebanyak $50.0 \%$, dan sedikit setuju adalah $2.5 \%$. Diikuti dengan saya memperbaiki rupa bentuk pembungkusan produk $(\min =5.45)$ dengan jumlah peratus responden yang sangat setuju adalah sebanyak $45.0 \%$ dan setuju adalah sebanyak $55.0 \%$. Manakala, item pernyataan saya memperbaiki reka grafik pembungkusan $(\min =5.40)$ dengan jumlah peratus responden yang sangat setuju adalah sebanyak $50.0 \%$, setuju adalah sebanyak $40.0 \%$, dan sedikit setuju adalah $10.0 \%$. Bagi item saya memperbaiki warna pembungkusan $(\min =5.40)$ dengan jumlah peratus responden yang sangat setuju adalah sebanyak $45.0 \%$, setuju adalah sebanyak $50.0 \%$, dan sedikit setuju adalah $5.0 \%$. Seterusnya, item saya menghasilkan pembungkusan yang berkualiti $(\min =5.37)$ dengan jumlah peratus responden yang sangat setuju adalah sebanyak $47.5 \%$, setuju adalah sebanyak $45.0 \%$, sedikit setuju adalah $5.0 \%$ dan kurang setuju adalah $2.5 \%$. Item pernyataan saya menggunakan kaedah atau teknik pembungkusan yang lebih baik $(\mathrm{min}=5.27)$ dengan jumlah peratus responden yang sangat setuju adalah sebanyak $42.5 \%$, setuju adalah sebanyak $42.5 \%$, dan sedikit setuju adalah sebanyak $15.0 \%$. Manakala, saya menggunakan bahan pembungkus yang lebih sesuai $(\mathrm{min}=5.25)$ dengan jumlah peratus responden yang sangat setuju adalah sebanyak $35.0 \%$, setuju adalah sebanyak $55.0 \%$, dan sedikit setuju adalah $10.0 \%$, dan terakhir adalah saya menggunakan bahan pembungkus yang mesra alam $(\mathrm{min}=5.02)$ dengan jumlah peratus responden yang sangat setuju adalah sebanyak $35.0 \%$, setuju adalah sebanyak $37.5 \%$, sedikit setuju adalah $22.5 \%$ dan kurang setuju adalah $5.0 \%$.

Oleh itu, dapat diringkaskan bahawa item 5 iaitu "Saya memperbaiki informasi maklumat pada pembungkusan" dan item 4 iaitu "saya memperbaiki rupa bentuk pembungkusan produk" mencatatkan min yang tertinggi iaitu 5.45 dan mencatatkan jumlah sebanyak $97.5 \%$ responden yang setuju dan sangat setuju pada item tersebut dan $100 \%$ responden yang setuju dan sangat setuju pada item tersebut. Manakala item 2 iaitu "Saya menggunakan bahan pembungkus yang mesra alam" mencatatkan min yang terendah iaitu 5.02 dan mencatatkan jumlah sebanyak $72.5 \%$ responden yang setuju dan sangat setuju pada item tersebut dan $27.5 \%$ responden yang sedikit sedtuju dan kurang setuju dengan pernyataan item yang diberikan. Secara keseluruhannya menunjukkan bahawa jumlah purata peratus bagi responden yang sangat setuju adalah sebanyak $43.4 \%$ dan setuju adalah sebanyak $46.9 \%$, diikuti sedikit setuju adalah $8.8 \%$ dan kurang setuju adalah $0.9 \%$. Ini bermakna tahap amalan inovasi pembungkusan usahawan mikro selepas menyertai program bimbingan agensi menunjukkan $90.3 \%$ ada melakukan inovasi pembungkusan yang bersifat drastik dan hanya $9.7 \%$ usahawan mikro yang melakukan inovasi pembungkusan bertindak secara perlahan. Manakala, skor amalan inovasi pembungkusan usahawan mikro selepas menyertai bimbingan agensi pula berada pada tahap yang tinggi $(\min =5.33)$.

Jadual 2: Analisis tahap amalan inovasi pembungkusan bagi setiap item pernyataan

\begin{tabular}{llccccc}
\hline No & $\begin{array}{l}\text { Selepas menyertai program pembungkusan } \\
\text { bimbingan agensi... }\end{array}$ & $\begin{array}{c}\text { KS } \\
(\mathbf{\%})\end{array}$ & $\begin{array}{c}\text { SeS } \\
\mathbf{( \% )}\end{array}$ & $\begin{array}{c}\text { S } \\
(\mathbf{\% )}\end{array}$ & $\begin{array}{c}\text { SS } \\
\mathbf{( \% )}\end{array}$ & Min \\
\hline 1 & $\begin{array}{l}\text { Saya menggunakan bahan pembungkus yang lebih } \\
\text { sesuai. }\end{array}$ & 0.0 & 10.0 & 55.0 & 35.0 & 5.25 \\
2 & $\begin{array}{l}\text { Saya menggunakan bahan pembungkus yang mesra } \\
\text { alam. }\end{array}$ & 5.0 & 22.5 & 37.5 & 35.0 & 5.02 \\
3 & $\begin{array}{l}\text { Saya menggunakan kaedah atau teknik pembungkusan } \\
\text { yang lebih baik. }\end{array}$ & 0.0 & 15.0 & 42.5 & 42.5 & 5.27 \\
& & & & &
\end{tabular}


DOI: https://doi.org/10.47405/mjssh.v5i1.347

\begin{tabular}{llccccc}
4 & $\begin{array}{l}\text { Saya memperbaiki rupa bentuk pembungkusan } \\
\text { produk. }\end{array}$ & 0.0 & 0.0 & 55.0 & 45.0 & 5.45 \\
5 & 0.0 & 2.5 & 50.0 & 47.5 & 5.45 \\
& $\begin{array}{l}\text { Saya memperbaiki informasi maklumat pada } \\
\text { pembungkusan. }\end{array}$ & & & & & \\
6 & Saya memperbaiki warna pembungkusan. & 0.0 & 5.0 & 50.0 & 45.0 & 5.40 \\
7 & Saya memperbaiki reka grafik pembungkusan. & 0.0 & 10.0 & 40.0 & 50.0 & 5.40 \\
8 & Saya menghasilkan pembungkusan yang berkualiti. & 2.5 & 5.0 & 45.0 & 47.5 & 5.37 \\
\hline & Purata Peratus dan Min Keseluruhan & 0.9 & 8.8 & 46.9 & 43.4 & 5.33 \\
\hline
\end{tabular}

Nota: KS - Kurang setuju, SeS - Sedikit setuju, S - Setuju, SS - Sangat setuju

Penemuan ini menunjukkan bahawa selepas menyertai program pembungkusan bimbingan agensi, usahawan mikro ada mengaplikasikan ilmu yang diperolehi dengan melakukan penambahbaikan terhadap penampilan pembungkusan produk. Perkara utama yang mereka lakukan adalah memperbaiki informasi maklumat, rupa bentuk, warna dan reka grafik pada pembungkusan selepas mendapat bimbingan agensi. Kajian Fernqvist, Olsson dan Spendrup (2015) dan Maleki, Amiri Aghdaie, Shahin, dan Ansari (2019) mendapati, semasa membeli-belah pengguna lebih mementingkan informasi maklumat, rupa bentuk, warna dan reka grafik yang dipaparkan pada pembungkusan berbanding bahan pembungkus. Hal ini menunjukkan bahawa adanya pengaruh pengguna yang mendorong usahawan mikro untuk melakukan perubahan pada pembungkusan. Malah kajian Getz dan Robinson (2003) membuktikan bahawa hampir 80 peratus idea inovatif datangnya daripada individu dan Arum Etikariena dan Hamdi Muluk (2014) pula menyatakan, 20 peratus idea adalah daripada inisiatif agensi. Oleh itu, usahawan mikro yang mempunyai sifat inovatif berupaya menghasilkan pembungkusan yang lebih berinovasi.

Dapatan kajian juga menunjukkan usahawan mikro kurang memfokuskan inovasi pembungkusan dalam aspek penggunaan bahan pembungkus yang lebih berkualiti dan sesuai, penambahbaikan kaedah atau teknik pembungkusan dan penggunaan bahan pembungkus yang mesra alam seperti mana yang dikemukakan dalam kajian Mukhari dan Mazilah (2011) yang mendapati, usahawan yang menggunakan bahan pembungkus yang lebih sesuai adalah berada pada tahap sederhana. Penemuan ini juga menjawab kepada persoalan kajian dan objektif kajian serta memperkukuhkan pernyataan masalah yang dikemukakan oleh Ahmad Zaki (2011) dan Anon. (2014), (2018d) yang menyatakan produk usahawan sukar memasuki pasaraya disebabkan oleh penggunaan bahan pembungkus yang tidak berkualiti dan kaedah pembungkusan yang kurang sesuai. Dapatan kajian juga menunjukkan penggunaan pembungkusan mesra alam adalah kurang diberi perhatian sedangkan kajian Auliandri, Thoyib,Rohman, dan Rofiq (2018) menyatakan pengguna yang berusia muda lebih mementingkan pembungkusan yang mempunyai ciri-ciri mesra alam.

Justeru, usahawan mikro perlu lebih melakukan dan memfokuskan inovasi pembungkusan dari aspek penggunaan bahan pembungkus yang lebih sesuai dan berkualiti, penambahbaikan kaedah atau teknik pembungkusan dan penggunaan bahan pembungkus yang mesra alam di samping penambahbaikan informasi maklumat, rupa bentuk, warna dan reka grafik bagi menjamin kualiti yang berpanjangan dan dapat menembusi pasaraya. Agensi pembimbing juga perlu memainkan peranan lebih dalam memberikan penekanan kepada usahawan agar menggunakan bahan pembungkus yang lebih sesuai dan berkualiti, meningkatkan kaedah atau teknik pembungkusan sedia ada dan menggunakan bahan pembungkus yang mesra alam.

\section{Kesimpulan}

Secara keseluruhan, tahap amalan usahawan dalam menghasilkan inovasi pembungkusan adalah berada pada tahap yang tinggi. Amalan atau tingkah laku seseorang usahawan untuk melaksanakan pembungkusan yang berinovasi adalah dipengaruhi oleh kecenderungan untuk melaksanakannya. Kecenderungan ini dipengaruhi oleh diri usahawan dan sokongan agensi pembimbing untuk melakukan sesuatu tindakan seperti mana dalam Teori Tingkahlaku Terancang (TPB) (Ajzen 1991). Teori ini meramalkan tingkah laku adalah disengajakan kerana tingkah laku boleh dibincangkan dan dirancang dengan beranggapan bahawa perilaku manusia berlaku dalam keadaan yang sedar dan 
DOI: https://doi.org/10.47405/mjssh.v5i1.347

mempertimbangkan segala informasi yang tersedia. Oleh itu, usahawan perlu melakukan strategi melihat, membandingkan dan menambahbaik melalui pemerhatian produk pesaing. Strategi ini tidak dianggap "sulit" dalam sesebuah perniagaan bagi menghasilkan produk yang berbeza dari pesaing (Baharuddin, 2009). Strategi ini akan memberikan impak yang positif di dalam perniagaan dan pemasaran kerana produk yang dihasilkan adalah berbeza dan unik. Cadangan kajian pada masa akan datang adalah mengukur tahap amalan inovasi pembungkusan di kalangan usahawan yang tidak mendapat bimbingan agensi bagi melihat perbandingan.

\section{Rujukan}

Ahmad Zaki, I. (2011). Formula usahawan berjaya. Edisi ke-1. Utusan Publications \& Distributors Sdn Bhd.

Ajzen, I. (1991). The theory of planned behavior. Organizational Behavior and Human Decision Processes 50(2): 179-211.

Alfoqahaa, S. (2018). Critical success factors of small and medium-sized enterprises in Palestine. Journal of Research in Marketing and Entrepreneurship 20(2): 170-188.

Ampuero, O. \& Vila, N. (2006). Consumer perceptions of product packaging. Journal of Consumer Marketing 23(2): 100-112.

Anon. (2014). Giant tidak pinggir produk usahawan IKS. Utusan Online, 29 September. Kota Kinabalu. http://www.utusan.com.my/bisnes/usahawan/giant-tidak-pinggir-produk-usahawan-iks1.7835 .

Anon. (2018a). Packaging Survey Analysis Executive Insights 2018. https://www.lek.com/sites/default/files/insights/pdf-attachments/20XX-Packaging-Survey.pdf [5 December 2018].

Anon. (2018b). Pasar raya diminta beri ruang PKS jual produk. Berita Harian, 6. Putrajaya. http://www.med.gov.my/portal/document/files/Keratan Akhbar/2018/Oktober/Makluman Media 10 Oktober 2018 -Kementerian Pembangunan Usahawan.pdf.

Anon. (2018c). DPMM sasar migrasi 50 peratus usahawan mikro melayu ke pks menjelang 2020. Utusan Borneo (Sabah). Seri Kembangan, Selangor. https://www.utusanborneo.com.my/2018/03/01/dpmm-sasar-migrasi-50-peratus-usahawan-mikromelayu-ke-pks-menjelang-2020.

Anon. (2018d). Jaga kualiti produk. Harian Metro https://www.hmetro.com.my/hati/2018/05/341946/jaga-kualiti-produk.

Arum Etikariena \& Hamdi Muluk. (2014). Hubungan antara memori organisasi dan perilaku inovatif karyawan. Makara Hubs-Asia 18(2): 77-88.

Atiqah, N., Binti, S., Nazri, A. \& Azmi, A. (2016). The challenges managing brand positioning: Small Medium Entreprises ' ( SME) In Malaysia. International Journal of Business and Management Invention ISSN (Online) 5(12): 2015-2016. www.ijbmi.org.

Auliandri, T.A., Thoyib, A., Rohman, F. \& Rofiq, A. (2018). Does green packaging matter as a business strategy? Exploring young consumers' consumption in an emerging market. Problems and Perspectives in Management 16(2): 376-384.

Azad, N. \& Masoumi, M. (2012). The Impact of Packaging on Product Competition. Management Science Letters 2(8): 2789-2794.

Baharuddin, I. (2009). Asas Pengurusan Pemasaran. Shah Alam, Selangor: Pusat Penerbitan Universiti (UPENA), Universiti Teknologi MARA.

Beneke, J., Mathews, O., Munthree, T. \& Pillay, K. (2015). The role of package colour in influencing purchase intent of bottled water: Implications for SMEs and entrepreneurs. Journal of Research in Marketing and Entrepreneurship 17(2): 165-192.

Esa, A., Ab. Hadi, M.Y. \& Mohd Yunos, J. (2002). Persidangan_UKM_2002b. Prosiding Persidangan Kebangsaan Etika Gunaan dan Profesional. hlm. 31-38. Bangi: UKM: ISBN 983-9122-04-5.

Fernqvist, F., Olsson, A. \& Spendrup, S. (2015). What's in it for me? Food packaging and consumer responses, a focus group study. British Food Journal 117(3): 1122-1135.

Getz, I. \& Robinson, A.G. (2003). Innovate or die: is that a fact? Creativity and Innovation Management 12(3): 130-136. 
Malaysian Journal of Social Sciences and Humanities (MJSSH), Volume 5, Issue 1, (page 1 - 8), 2020

DOI: https://doi.org/10.47405/mjssh.v5i1.347

Hair, J., Money, A., Page, M. \& Samouel, P. (2007). Research Methods for Business. United States of America: John Wiley \& Sons, Ltd.

Islam, N. \& Muktadir-Al-Mukit, D. (2016). Factors Determining the Success of SMEs in Bangladesh. SSRN https://doi.org/10.2139/ssrn.2851533.

Jeff Pruchnic, Susak, C., Grogan, J., Primeau, S., Torok, J., Trimble, T., Foster, T. \& Barton, E. (2018). Slouching toward sustainability: Mixed methods in the direct assessment of student writing. The Journal of Writing Assessment 11(1): 1-15. http://journalofwritingassessment.org/article.php?article $=125$.

Jernström, E., Karvonen, V., Kässi, T., Kraslawski, A. \& Hallikas, J. (2017). The main factors affecting the entry of SMEs into bio-based industry. Journal of Cleaner Production 141: 1-10.

Kalsonm, A.W. \& Ab.Rahim, H. (2015). The understanding of small firm performance and the influence of entrepreneurial marketing on SMEs in Malaysia. Journal of Creative Writing 1(3): $25-37$.

Kiumarsi, S., Jayaraman, K., Salmi, M.I. \& Varastegani, A. (2014). Marketing strategies to improve the sales of bakery products of small-medium enterprise (SMEs) in Malaysia. International Food Research Journal 21(6): 2101-2107.

Kotler, P. \& Armstrong, G. (2012). Principles of Marketing. Edisi ke-14. United States of America: Pearson Prentice Hall.

Kurtkoti, A. (2016). factors influencing consumer buying decision process for different products and brands. Sankalpa:Journal of Management \& Research 6(1): 1-16. https://search.proquest.com/docview/1807690548?accountid=169017.

Luminer, Lakewood \& N.J. (2017). Survey: How shoppers respond to packaging, labeling on crowded store shelves | 2017-10-16 | Refrigerated Frozen Food. Refrigerated \& Frozen Foods https://www.refrigeratedfrozenfood.com/articles/93684-survey-how-shoppers-respond-topackaging-labeling-on-crowded-store-shelves [18 February 2019].

Magnier, L., Schoormans, J. \& Mugge, R. (2016). Judging a product by its cover: Packaging sustainability and perceptions of quality in food products. Food Quality and Preference 53: 132142.

Maleki, S., Amiri Aghdaie, S.F., Shahin, A. \& Ansari, A. (2019). Investigating the relationship among the Kansei-based design of chocolate packaging, consumer perception, and willingness to buy. Journal of Marketing Communications 1-21.

Mukhari, A.W. \& Mazilah, I. (2011). persepsi pengendali-pengendali makanan terhadap amalan kebersihan dan keselamatan di Taman Seri Pulai, Johor. Journal of Technical, Vocational \& Engineering Education 2(June): 1-17.

Raosoft. (2004). Sample Size Calculator by Raosoft, Inc. Sample size http://www.raosoft.com/samplesize.html.

Sayal, A. \& Banerjee, S. (2017). Factors influencing performance of SMEs: Literature review and research propositions for SMEs. Marketing Review 17(1): 3-32.

Sazrinee, Z.A., Raja Ahmad Azmeer, R.A.E., Rahinah, I. \& Muhammad Zaffwan, I. (2014). A semantic approach in perception for packaging in the SME's food industries in Malaysia: A case study of Malaysia Food product branding in United Kingdom. Procedia - Social and Behavioral $\begin{array}{lll}\text { Sciences } & \text { 115(Iicies 115-130. }\end{array}$ http://linkinghub.elsevier.com/retrieve/pii/S1877042814019685.

Siti Hasnah, H., Wai Leng, L. \& Wong Wai, P. (2012). The influence of food product packaging attributes in purchase decision: A study among consumers in Penang, Malaysia. Journal of Agribusiness Marketing 5: 14-28.

SME Corporation, M. (2018). Dunia yang berhubung: Pendigitalan PKS. Malaysia.

Suhaila, N., Suhaily, S. \& Muhammad Firdaus, M.S. (2014). Faktor-faktor penyumbang kepada kejayaan dan kegagalan Perusahaan Kecil dan Sederhana (PKS) Bumiputera di Malaysia. Conference on Management and Muamalah (CoMM 2014) (1) hlm. 1-5 https://doi.org/10.1007/s13398-014-0173-7.2.

Suraiya, I., Abd Hair, A., Mohd Yusof, H., Ahmad Raflis, C.O., Sarmila, M.S., Suhana, S., Zaimah, R. \& Azima, A.M. (2015). Penelitian tingkah laku inovasi firma makanan halal kecil di Malaysia: Satu analisis tentatif. GEOGRAFIA OnlineTM Malaysian Journal of Society and Space 11(2): 64-76. 
Malaysian Journal of Social Sciences and Humanities (MJSSH), Volume 5, Issue 1, (page 1 - 8), 2020

DOI: https://doi.org/10.47405/mjssh.v5i1.347

Suwardi Afandi, A. \& Mohd Arif, W. (2014). Persepsi pengeluar snek terhadap pembungkusan dan pelabelan. Economic and Technology Management Review 9b: 155-162.

Tinne, W.. (2016). Impact of packaging on consumer buying behaviour at Dhaka City. Global Disclosure of Economics and Business 5(2): 93-100. http://iproclaim.my/archive/index.php/gdeb/article/view/250.

Wang, J. \& Shapira, P. (2012). Partnering with universities: A good choice for nanotechnology startup firms? Small Business Economics 38(2): 197-215.

Wells, L.E., Farley, H. \& Armstrong, G.A. (2007). The importance of packaging design for own-label food brands. International Journal of Retail \& Distribution Management 35(9): 677-690.

Wyrwa, J. \& Barska, A. (2017). Packaging as a source of information about food products. Procedia Engineering 182: 770-779.

Zaim Shah, A. \& Hartini, A. (2016). Inovasi dalam Perusahaan Kecil dan Sederhana (PKS) pembuatan makanan \& minuman. Journal of Global Business and Social Entrepreneurship 1(1): 79-88.

Zekiri, J. \& Hasani, V.V. (2015). The role and impact of the packaging effect on consumer buying behaviour. Ecoforum 4(1): 232-240. 